\title{
Desafios para o Futuro da Psicologia: Contribuições da Psicologia na Construção do Conhecimento no Século XXI
}

Challenges For The Future Of Psychology: Contributions Of Psychology In The Construction Of Knowledge In The Xxi Century

Desafíos Para El Futuro De La Psicología: Contribuciones De La Psicología En La Construcción Del Conocimiento En El Siglo XXI
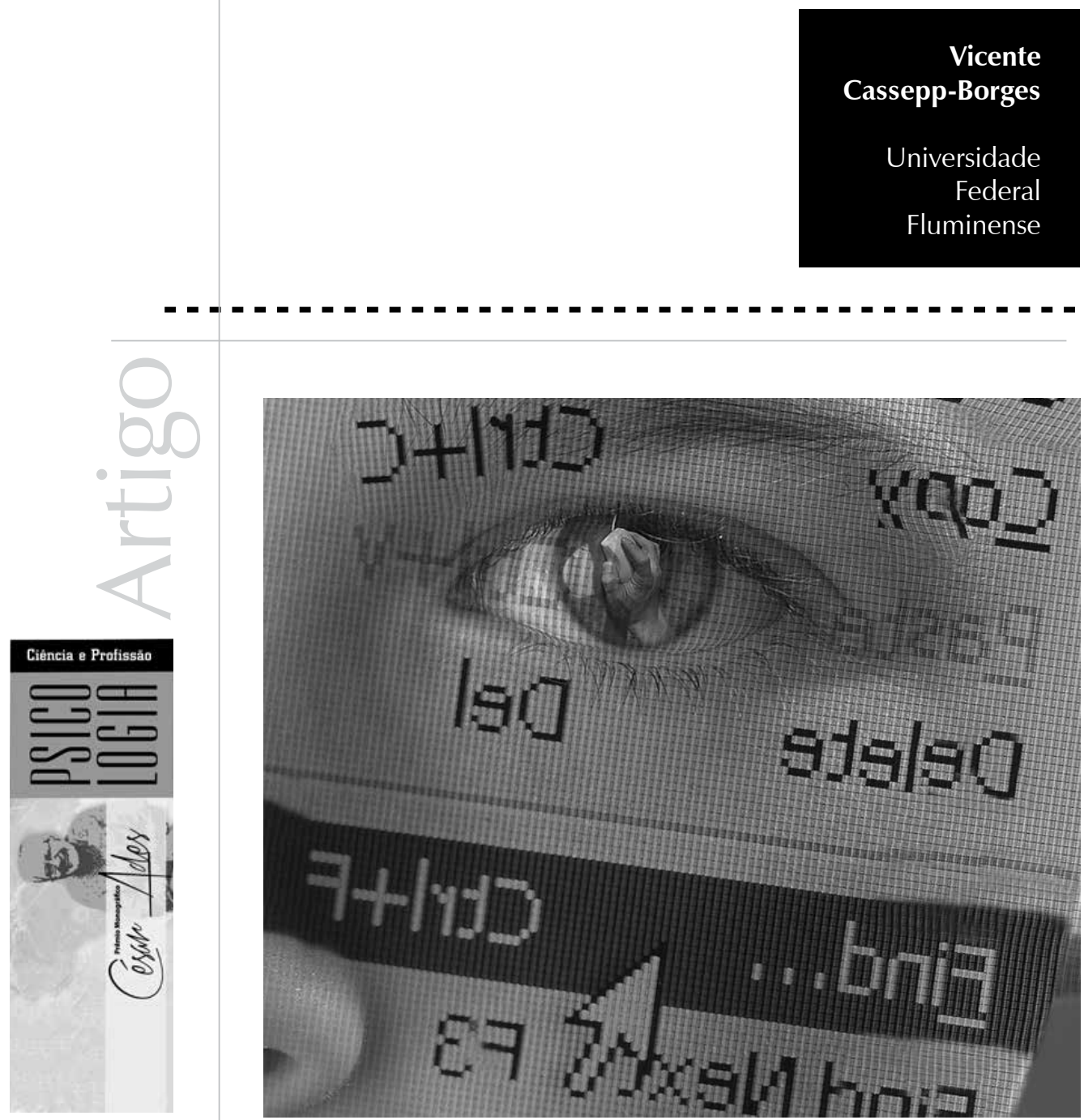
Resumo: O objetivo deste ensaio foi refletir sobre o futuro da Psicologia como área do conhecimento e ciência aplicada. São abordadas as maneiras como a Psicologia pode provocar as mudanças da sociedade que devem ocorrer no século XXI e adaptar-se a elas. São apresentadas as visões skinnerianas do futuro da Psicologia, afirmando que o avanço da área pode trazer a solução para a maioria dos problemas da humanidade. O efeito Flynn é apontado como força produtora de mudanças psicológicas e sociais, pois a humanidade será composta por pessoas mais inteligentes, que devem desenvolver a Psicologia e dela necessitar. Psicólogos mais inteligentes construirão uma área cada vez mais sustentada em evidências empíricas. É assinalada a necessidade de a Psicologia se especializar, rever seus currículos em nível de graduação e unir-se em torno de um paradigma integrador. Conclui-se afirmando a necessidade de valorizar as opiniões de jovens psicólogos, além de criar melhores formas de interação entre pessoas e máquinas.

Palavras-chave: História da Psicologia. Psicologia aplicada. Pesquisa Científica - Psicologia. Paradigma.

Abstract: The aim of this essay was to reflect on the future of psychology as a field of knowledge and applied science. The ways in which psychology can cause the changes in society that must occur in the XXI century and adapt to them are approached. Skinner's views of the future of psychology are displayed, arguing that the progress in the area can bring the solution for most problems of humanity. The Flynn effect (1987) is pointed out as a force producer of psychological and social changes, because humanity will be composed of more intelligent people, who should develop psychology and also need it. Smart psychologists will build an area increasingly supported by empirical evidence. It is signaled the need of psychology to specialize and review its schedules at the undergraduate level and unite around an integrative paradigm. It was concluded by stating the need to value young psychologists' opinions, in addition to the creation of better ways of interaction between people and machines.

Keywords: History of psychology. Applied psychology. Scientific research - Psychology. Paradigm.

Resumen: El objetivo de este ensayo fue reflexionar sobre el futuro de la Psicología como área del conocimiento y ciencia aplicada. Son abordadas las maneras como la Psicología puede provocar los cambios de la sociedad que deben ocurrir en el siglo XXI y adaptarse a ellas. Son presentadas las visiones skinnerianas del futuro de la Psicología, afirmando que el avance del área puede traer la solución para la mayoría de los problemas de la humanidad. El efecto Flynn es apuntado como fuerza productora de cambios psicológicos y sociales, pues la humanidad estará compuesta por personas más inteligentes, que deben desarrollar la Psicología y precisar de esta. Psicólogos más inteligentes construirán un área cada vez más sostenida en evidencias empíricas. Es señalada la necesidad de que la Psicología se especialice, revise sus currículos en nivel de graduación y se una en torno a un paradigma integrador. Se concluye afirmando la necesidad de valorar las opiniones de jóvenes psicólogos, además de crear mejores formas de interacción entre personas y máquinas.

Palabras clave: Historia de la Psicología. Psicología aplicada. Investigación Científica - Psicología. Paradigma.

A reflexão sobre o futuro da Psicologia ou de qualquer outra área constitui assunto difícil e que pode gerar polêmicas. É algo pouco discutido, possivelmente pelo fato de não existirem dados para serem coletados. Para pesquisar a história da Psicologia, o método utilizado é simplesmente observar como as coisas ocorreram. Pode-se obter relatos de pessoas que vivenciaram a história, documentos de épocas passadas e revisão de artigos científicos ou não, dentre outras fontes. No entanto, o futuro ainda não aconteceu, e não existem indícios sobre ele. Os dados disponíveis sobre o futuro são os acontecimentos passados e seus desdobramentos, além da situação presente. Analisar uma conjuntura atual ou passada envolve diversas variáveis, a maioria inacessível ao conhecimento, sendo essa uma tarefa complexa. O entendimento sobre todas essas variáveis tem de ser muito profundo, pois no futuro haverá novas variáveis que simplesmente desconhecemos, mas que alterarão profundamente o curso dos fatos. E variáveis podem ser manipuladas, ou seja, somos construtores da Psicologia do século $\mathrm{XXI}$.

Ardila (2011) teve uma contribuição importante na discussão do futuro da Psicologia ao reunir 50 psicólogos com destaque internacional, oriundos de diversas localidades do mundo, para abordar suas visões sobre o futuro da Psicologia. O autor 
Resenhando a obra de Ardila (201 1), CasseppBorges (2011) complementa que o futuro da Psicologia está associado ao futuro da tecnologia. sustenta que a Psicologia do futuro deverá apresentar maior ênfase na ciência, maior ênfase na temática social, teorizações e utilização de modelos matemáticos, trabalhos sobre problemas complexos, maior profissionalização e especialização e integração da Psicologia em torno de um paradigma unificador. Resenhando a obra de Ardila (2011), Cassepp-Borges (2011) complementa que o futuro da Psicologia está associado ao futuro da tecnologia. $\mathrm{O}$ fato de o mapeamento cerebral se tornar mais barato e portátil no futuro tende a facilitar a criação de modelos cognitivos cada vez mais acurados, por exemplo.

Por maior que seja o embasamento teórico, por melhor que seja o método utilizado para prever o futuro, não há como fugir do exercício especulativo, que envolve a subjetividade. Prever o futuro ainda deve ser feito com base em um exercício de realismo, ou seja, as previsões não podem ser demasiadamente otimistas nem demasiadamente pessimistas. Não se pode ignorar nas previsões o fato de que as pessoas podem trabalhar na construção de um futuro mais desejável, não sendo meras vítimas dos acontecimentos. Com esse ensaio, pretendese abordar diversas previsões, algumas pessimistas e outras otimistas. Todas tratam de especulações, mas com fundamento no conhecimento existente e disponível hoje em dia.

\section{Skinner e o futuro da Psicologia}

Não há como negar a importância do pensamento de Skinner sobre o futuro da Psicologia. Dentre os grandes pensadores da área, ele provavelmente foi aquele que mais refletiu sobre os desdobramentos que tomaria essa ciência. Em O Mito da Liberdade, Skinner (1972a) levanta a necessidade de haver uma ciência do comportamento para resolver os problemas que o mundo enfrentaria, como a ameaça de um holocausto nuclear, a explosão populacional ou a destruição do meio ambiente. Dessa maneira, previu que soluções mais eficazes para esses problemas no futuro envolveriam a Psicologia, em vez das engenharias. Isso significa que, melhor do que desenvolver mísseis de defesa antibalística, é convencer as pessoas a não dispararem os mísseis de ataque, melhor do que criar métodos anticoncepcionais inovadores é convencer as pessoas a usá-los, melhor do que desenvolver tecnologias menos poluentes é convencer as pessoas a não poluir. Assim, o futuro da humanidade depende do avanço da Psicologia como área do conhecimento.

Na tentativa de explicar a importância de uma psicologia científica para uma sociedade no futuro, Skinner (1972c) escreveu o romance Walden II. Nessa obra, foi criada uma sociedade utópica, na qual as pessoas são educadas pelos princípios da análise do comportamento. A ideia básica do livro é a de que, se é possível educar por meio de reforçamento positivo, deveríamos fazer isso, pois é um meio de educar com o qual as pessoas se sentem mais felizes. A obra inspirou algumas sociedades alternativas reais, como Twin Oaks, nos Estados Unidos, e Los Horcones, no México, que persistem até hoje, e também inspirou o romance Walden III, que tentou ampliar a experiência de uma sociedade alternativa para um país (Ardila, 1979). Walden II foi uma previsão do futuro que se tornou realidade, e o desenvolvimento da Psicologia pode tornar a utopia ainda mais ampla.

\section{O efeito Flynn e seus efeitos no futuro da humanidade e da Psicologia}

Mudanças sociais ocorrem, no entanto, pouco crédito se dá às características cognitivas das pessoas que promovem as mudanças. 
Assim, não seria exagero atribuir o papel de agente causador das mudanças sociais a algo que pesquisadores da área da inteligência denominam efeito Flynn (1987). Existem demonstrações, com sólidas bases científicas, de que a cada geração aumentam o número de acertos em testes de inteligência (Silva, 2003), ou seja, cada nova geração é mais inteligente do que a geração que a antecedeu. Esse efeito é extremamente grande, na ordem de 18 pontos ou mais em um teste de QI para inteligência fluida (Silva, 2003), que é avaliada por provas não verbais e que tem menor dependência de influências culturais (Schelini, 2006). Ocorre que existe um avanço tecnológico e computacional que está modificando a maneira como as pessoas são estimuladas, e pessoas mais inteligentes tendem a criar máquinas que estimulem cada vez mais o cérebro humano. Isso pode ser uma forma de potencializar o efeito Flynn. Assim, com a humanidade sendo composta por pessoas mais inteligentes, diversas mudanças sociais devem ocorrer, dentre elas:

\section{Aperfeiçoamento de sistemas políticos e de gestão}

A democracia provavelmente deve permanecer como um sistema político das nações hegemônicas. Há diversas máximas sugerindo que a democracia seja um sistema desejável como, por exemplo, "nunca houve uma guerra entre duas democracias", "a democracia não é um sistema perfeito, mas é o melhor que existe" ou "a democracia é o pior sistema político, depois de todos os outros". O aumento da inteligência humana deve servir para aperfeiçoar a democracia, não só no meio político mas também nos sistemas de gestão de escolas e de empresas, dentre outros. A democracia, para ser bem sucedida, depende da capacidade das pessoas de tomar as decisões corretas ou, em outras palavras, da inteligência.
A Psicologia, como ciência, não deve ficar alheia à melhoria desses sistemas, pois essa ciência tem potencial para ser uma das principais ciências de apoio dessa mudança. Por exemplo, assim como a área do Direito hoje contribui com a Lei da Ficha Limpa, a Psicologia do futuro poderá contribuir com o que poderia ser chamado de Lei da Mente Limpa. Sabe-se que ambientes políticos são um terreno fértil para pessoas com capacidade de manipular as outras a fim de obter benefícios pessoais (leia-se psicopatas). Com o avanço das técnicas de avaliação psicológica que provavelmente ocorrerá no futuro, inclusive a partir de testes existentes hoje, como o PCL, Hare (2004), pode-se criar legislações de forma a barrar candidaturas de psicopatas a cargos públicos.

\section{Mentalidade científica}

O fato de termos pessoas mais inteligentes também deve favorecer uma mentalidade científica na sociedade, em todos os seus níveis. O pensamento científico implica que as pessoas tenham capacidade de, mesmo nas suas tarefas cotidianas, analisar hipóteses, observar variáveis, etc. Uma sociedade com pessoas inteligentes será mais científica, com as pessoas exigindo demonstrações de fatos e menos pessoas aceitando explicações sem demonstração empírica.

A Psicologia também deve tornar-se uma área mais científica, seguindo a tendência mundial. Psicólogos aplicados estarão em contato com o conhecimento produzido pela ciência, serão assinantes e leitores de revistas científicas, além de produtores de conhecimento. O aumento de leitores também fará com que aumente o número de cientistas que produzem conhecimento direcionado ao psicólogo aplicado. A ênfase na ciência, inclusive com maior utilização de modelos matemáticos e de pesquisas sobre temas complexos que não podem ser investigados hoje devido a limitações metodológicas, 
devem ser assuntos corriqueiros na Psicologia do futuro (Ardila, 2011).

\section{As máquinas e o futuro da Psicologia}

Não se pode esquecer que cada vez as máquinas se tornam mais humanas. Os avanços da inteligência artificial ocorrerão em níveis mais rápidos do que a humanidade possa acompanhar, evidentemente que acompanhados por um avanço da inteligência dos humanos que construirão essas máquinas. As pessoas do século XXI deverão desenvolver habilidades para relacionar-se tanto com humanos quanto com computadores.

Allan Turing (1950), tido como o pai da computação moderna, sugeriu um teste no qual uma pessoa estabeleceria um chat com um computador e com outra pessoa. Caso fosse impossível distinguir qual conversa havia sido estabelecida com o computador e qual havia sido estabelecida com a pessoa, poder-se-ia dizer que o computador pensava. A previsão para o futuro de Turing foi que seu desafio seria superado no final do século passado. E talvez tenha sido superado antes disso. Já existem computadores capazes de estabelecer diálogos com humanos, mesmo que com limitações. A derrota de Gary Kasparov para o computador Deep Blue em uma partida de xadrez, em 1997, também possui relação com o teste de Turing, pois a máquina jogou xadrez como se fosse humana, nas palavras do próprio Kasparov.

Para a Psicologia, existe a implicação de que o computador pode substituir o trabalho do psicólogo. Essa é uma realidade presente e que a Psicologia, como classe, precisa encarar. Se as máquinas já podem conversar com pessoas, não seria impossível que as máquinas pudessem fazer psicoterapia com pessoas. Essa tecnologia já existe
(Boronat Cortés, \& Barres Fabado, 2001), e é perfeitamente plausível que seja cada vez mais aperfeiçoada no futuro. Parece lógico que se diga que as máquinas nunca serão capazes de atuar como os humanos. Mas, cada vez que se levante alguma característica que humanos têm e que as máquinas não têm, a ciência trabalha para acrescentar tal atributo à máquina. E tem tido sucesso nisso.

Skinner (1972b) foi alvo de uma polêmica semelhante quando criou as máquinas de ensinar. Houve uma polêmica, pois muitos afirmavam que a máquina poderia substituir os professores. Skinner afirmou que um professor que fosse tão ruim que pudesse ser substituído por uma máquina mereceria ser substituído por uma delas. No entanto, temos que lidar com o fato de que hoje as máquinas (computadores) substituem professores na tarefa de ensinar. O conhecimento da humanidade avançou bastante, e irá avançar ainda mais pelo fato de termos máquinas ensinando humanos. Nenhum professor supera o material indexado pelo Google em conhecimento. É mais inteligente se aliar aos computadores do que tentar superá-los. Da mesma maneira, softwares de psicoterapia serão um concorrente ou aliado do futuro que os psicólogos de hoje deveriam tratar com mais seriedade.

Se, por um lado, as máquinas se tornarão cada vez mais humanas, por outro, a humanidade se tornará cada vez mais mecanizada. A causa comumente atribuída para esse fenômeno é a interação com as máquinas, mas não se pode esquecer o papel da inteligência humana nesse processo. Sabese que pessoas excepcionalmente mais inteligentes apresentam diversos problemas emocionais decorrentes disso (Alencar, 2007), ou seja, o efeito Flynn também terá consequências negativas, pois um aumento vertiginoso na inteligência humana também pode se refletir em um aumento do sofrimento psíquico humano. 
A Psicologia do século XXI precisa aperfeiçoar e massificar técnicas para acelerar também o desenvolvimento emocional, como o treinamento das habilidades sociais

(Del Prette \& Del Prette, 1999; Murta, 2005).
Por mais mecanizados que humanos se tornem, por mais humanizadas que as máquinas evoluam, não há perspectivas de que as máquinas consigam satisfazer algumas necessidades humanas, pelo menos em um futuro próximo. Dificilmente as máquinas saciarão a necessidade de afeto, de amor, de sexo e de alimentação, dentre outras. Analisando-se pela teoria humanista (Maslow, 1954), parece que as máquinas estão tendo cada vez mais a capacidade de satisfazer nossos desejos mais refinados, nossa capacidade de autorrealização sem, no entanto, atender as nossas necessidades primárias. Essas podem ser atendidas por humanos, mas o ser humano do futuro provavelmente será alguém com pouco contato com outros seres humanos, com todo o sofrimento psíquico decorrente disso, o que também possui relação com o efeito Flynn, pois, em pessoas muito inteligentes, geralmente há uma dessincronia, já que o desenvolvimento cognitivo é mais veloz que o desenvolvimento físico e emocional (Alencar, 2007). O psicólogo será o profissional mais capacitado para a função de humanizar a humanidade, de trazer o bem-estar para as pessoas. A Psicologia do século XXI precisa aperfeiçoar e massificar técnicas para acelerar também o desenvolvimento emocional, como o treinamento das habilidades sociais (Del Prette \& Del Prette, 1999; Murta, 2005). Por mais paradoxal que seja, as máquinas serão aliadas na construção do desenvolvimento emocional humano. Não se pode esquecer que a Psicologia é uma ciência, e as máquinas elevam o potencial de qualquer ciência, inclusive as humanas.

\section{Especialização da Psicologia}

Ao se analisar a maneira como os cursos de Psicologia são estruturados em comparação com os demais, pode-se dizer que a Psicologia é o curso de graduação com perspectivas mais amplas dentro de uma universidade. Dentre as áreas mais distintas do conhecimento, é difícil imaginar alguma que não possua a Psicologia aplicada àquela área. A Psicologia pode auxiliar praticamente qualquer área do conhecimento.

Além da amplitude na relação com as demais áreas, a Psicologia também é uma das áreas mais amplas dentro de si mesma, porque possui diversas correntes teóricas, todas muito distintas, ou seja, as diversas áreas do conhecimento humano também compõem a Psicologia. Assim, alguém que queira entender a Psicologia como um todo precisa deter conhecimentos em outras áreas. É impossível compreender a psicanálise sem compreender a Filosofia. Um psicometrista deve entender de Estatística, um neuropsicólogo deve ter conhecimentos de Biologia, um psicólogo social deve trabalhar com uma interface nas ciências sociais, um psicólogo escolar deve conhecer a Pedagogia, o psicólogo do trabalho deve dialogar com a Administração de Empresas, o psicólogo do esporte deve ler livros de Educação Física, e assim por diante. Isso significa que, para se compreender toda a Psicologia, deve-se compreender todo o conhecimento humano. A Psicologia se constituiu em uma área muito ampla, e é impossível conhecê-la em sua totalidade; são necessárias especializações.

Frente a isso, o Conselho Federal de Psicologia (2007) vem investindo no registro de especialidades. Esse é um caminho que a Psicologia do futuro deve adotar, o de ser uma área fragmentada. Por um lado, tal fato apresenta o aspecto negativo de diminuir o diálogo entre as diferentes áreas, mas, por outro, o fato de trabalharmos com profissionais especialistas traz pessoas com maiores conhecimentos para trabalhar com temáticas pontuais. As ciências tradicionais se dividiram em especialidades, e isso possibilitou seu desenvolvimento. A Psicologia, como uma ciência jovem, aos poucos está percebendo os ganhos de possuir profissionais e pesquisadores especialistas. 
Observando o exemplo da Medicina, seria natural imaginar que a Psicologia do futuro possa desenvolver um caminho semelhante. Uma das especializações da Medicina resultou na área da fisioterapia, outra resultou na Enfermagem, e o mesmo se pode dizer da Nutrição, da Fonoaudiologia e da Terapia Ocupacional, dentre outras, nas quais pode ser incluída a própria Psicologia. Não se pode esquecer que a Medicina é uma especialização da Biologia. Assim, é possível imaginar que a Psicologia do futuro possa ser a área mãe de diversas outras áreas. As subáreas da Psicologia podem ganhar status de áreas do conhecimento, inclusive com cursos de graduação específicos. Já está começando a surgir uma graduação em psicopedagogia. É muito plausível que avanços na modulação do comportamento levem à criação de um curso de graduação em Engenharia do Comportamento, vinculado à área das ciências exatas.

No entanto, apenas especializações não são suficientes. A Psicologia precisa reciclar-se como área no próprio ensino de graduação. É bastante perceptível que a área evoluiu bastante como ciência, mas os currículos de graduação pouco diferem dos currículos de 30 anos atrás. Algumas áreas emergiram e se consolidaram, embora possuam pouca representação nos cursos. Por exemplo, as neurociências serão, com certeza, uma área de destaque da Psicologia do século XXI, mas são representadas na graduação com poucas disciplinas, geralmente esquecidas no início dos cursos e ministradas por não psicólogos. A Psicologia jurídica tem sido uma área de atuação de muitos psicólogos, e, quando aparece na graduação, geralmente é ministrada como disciplina optativa. A Psicologia positiva tem ganhado um destaque internacional crescente desde sua criação
(Seligman \& Csikszentmihalyi, 2000) e deve ser uma das áreas hegemônicas da Psicologia do século XXI, apesar de muitos professores universitários brasileiros nem ao menos terem ouvido falar desse ramo.

O fato é que, na dimensão do ensino, o mundo e a Psicologia evoluem mais rápido do que a universidade, mesmo que a própria instituição produza conhecimentos de ponta em se tratando de pesquisa. A grade curricular dos cursos de Psicologia é rica em fatos e personagens históricos da área, mas pobre no estado da arte da ciência. É mais que urgente a reformulação dos currículos de Psicologia, para adequá-los ao que se espera dela e dos profissionais do século XXI.

\section{Paradigmas da Psicologia}

Com relação a paradigmas, as previsões são diferentes do que se prevê com relação às áreas da Psicologia. Um número cada vez maior de áreas emergentes deve surgir na Psicologia, mas a tendência para a Psicologia do futuro é a de se concentrar em um único paradigma integrador (Ardila, 2011). É difícil apontar qual seria esse paradigma diante da diversidade atual, mas é fácil apontar que esse paradigma será a ciência. Analisando-se a maneira como as outras áreas se consolidaram, percebe-se que sempre houve críticos afirmando que naquela área específica seria impossível fazer ciência. Mas o fato é que, seja na Física, na Química ou na Biologia, as áreas do conhecimento evoluíram quando os fenômenos foram observados e manipulados com um olhar científico.

A Psicologia de hoje apresenta diversas correntes teóricas distintas e muitas delas se sustentam na ciência. Pasquali (2003) lembra que as ciências exatas já passaram 
por uma Babel teórica. A França utilizava o pé do rei francês como medida padrão de comprimento, enquanto a Inglaterra utilizava o pé do rei inglês, o que criava confusões no comércio exterior entre os dois países. A superação dessas diferenças foi fundamental para a evolução das ciências exatas. Quando se desenvolvem manipulações atômicas, não há necessidade em verificar se estamos lidando com o átomo segundo Einstein ou segundo Bohr, pois o átomo é o mesmo para qualquer físico ou químico. No entanto, a compreensão de conceitos psicológicos ainda depende do autor utilizado. Uma palavra que deveria ser simples e corriqueira para a Psicologia, como mente, gera diversas discussões. O psicanalista entende de uma maneira, o cognitivista de outra e o behaviorista procura não entender. A mente deve ser o principal objeto de estudo da Psicologia em uma ciência unificada (Pasquali, 2008); mesmo assim não há um consenso entre os psicólogos sobre o que ela seja.

A diversidade da Psicologia é extremamente importante nos dias de hoje, pois não há uma demonstração empírica convincente sobre qual paradigma é o correto. Conforme as pesquisas surgem, os paradigmas vão apresentando falhas e contradições, e novos paradigmas surgem com lacunas pelo fato de não estarem completos, e aos poucos vão moldando-se conforme novos fatos são demonstrados e aceitos (Kuhn, 1972). A Psicologia do século XXI precisa observar quais as contradições existentes entre os diferentes paradigmas e fazer o debate sobre quais apresentam maiores evidências, precisa observar quais são as lacunas presentes no conhecimento e tentar preenchê-las. Muitas vezes, psicólogos procuram adequar suas observações empíricas aos paradigmas, quando o exercício a ser feito é justamente o contrário. O paradigma é que deve adequar-se à observação empírica. O século XXI é o momento no qual a Psicologia deve amadurecer, perdendo o pudor de derrubar teorias inadequadas à realidade.

\section{Conclusão}

A Psicologia é uma das ciências mais importantes na construção do futuro da humanidade, mas, antes disso, precisa construir a si própria. Novas gerações de psicólogos, cada vez mais inovadoras e inteligentes que as anteriores, resolverão os problemas atuais da área. A Psicologia precisa aprender a reconhecer esses talentos e a valorizar as ideias dos mais jovens para acelerar seu próprio desenvolvimento.

Não há dúvidas de que a humanidade irá evoluir do ponto de vista da criação de novas máquinas. No entanto, uma evolução que não seja associada a uma tecnologia psicológica pode ser caótica. É essencial que as pessoas sejam felizes com as suas bugigangas. Embora tenhamos a crença de que a felicidade nasce espontaneamente nas pessoas, isso somente ocorrerá se houver uma sociedade que favoreça o bem-estar humano. E a Psicologia tem um papel fundamental na construção dessa sociedade. Pode-se afirmar com otimismo que os psicólogos, cada vez mais inteligentes, terão competência para executar a tarefa. 


\section{Vicente Cassepp-Borges}

Doutor em Psicologia Social pela Universidade de Brasília e docente da Universidade Federal Fluminense,

Volta Redonda - RJ - Brasil.

E-mail: cassepp@gmail.com

Endereço para envio de correspondência:

Universidade Federal Fluminense - Polo Universitário de Volta Redonda - Instituto de Ciências Humanas e Sociais de Volta

Redonda - Rua Desembargador Ellis Hermydio Figueira, 783, Bloco A, Sala 214A, Bairro Aterrado.

CEP: 27213415. Volta Redonda, RJ. 
Alencar, E. M. L. S. de. (2007). Características sócio-emocionais do superdotado: questões atuais. Psicologia em Estudo, 12(2), 371-378. doi: http://dx.doi.org/10.1590/S141373722007000200018

Ardila, R. (1979). Walden Tres. Barcelona: CEAC.

Ardila, R. (2011). A psicologia no futuro: os psicólogos mais destacados no mundo falam sobre o futuro de sua disciplina. São Paulo: Vetor.

Cassepp-Borges, V. (2011). Progresso, ciência e tecnologia: resenha de A Psicologia no futuro: os psicólogos mais destacados do mundo falam sobre o futuro de sua disciplina, Aletheia, 34, 187-189.

Conselho Federal de Psicologia. (2007). Resolução $n^{\circ}$ 013, de 14 de setembro de 2007. Brasília, DF: Autor.

Del Prette, Z. A. P., \& Del Prette, A. (1999). Psicologia das habilidades sociais: terapia e educação. Petrópolis, RJ: Vozes.

Flynn, J. R. (1987). Massive IQ gains in 14 nations: What IQ tests really measure. Psychological Bulletin, 101(2), 171-191. doi:10.1037/0033-2909.101.2.171

Hare, R. D. (2004). Manual Escala Hare PCL-R: critérios para pontuação de psicopatia revisados (Versão brasileira: $\mathrm{H}$. Morana). São Paulo: Casa do Psicólogo.

Kuhn, T. (1972). The structure of scientific revolutions. Chicago: Chicago University Press.

Maslow, A. H. (1954). Motivation and personality. New York, NY: Harper.
Murta, S. G. (2005). Aplicações do treinamento em habilidades sociais: análise da produção nacional. Psicologia: Reflexão e Crítica, 18(2), 283-291. doi: http://dx.doi.org/10.1590/S010279722005000200017

Pasquali, L. (2003). Psicometria: teoria dos testes na psicologia e educação. Petrópolis, RJ: Vozes.

Pasquali, L. (2008). A ciência da mente: a psicologia à procura do objeto. Brasília, DF: Autor.

Schelini, P. W. (2006). Teoria das inteligências fluida e cristalizada: início e evolução. Estudos de Psicologia, 11(3), 323-332. doi: http://dx.doi.org/10.1590/S1413-294X2006000300010

Seligman, M. E. P., \& Csikszentmihalyi, M. (2000). Positive psychology: An introduction. American Psychologist, 55(1), 5-14.

Silva, J. A. da. (2003). Inteligência humana: abordagens biológicas e cognitivas. São Paulo: Lovise.

Skinner, B. F. (1972a). O mito da liberdade. Rio de Janeiro: Bloch.

Skinner, B. F. (1972b). Tecnologia do ensino. São Paulo: Edusp.

Skinner, B. F. (1972c). Walden II: uma sociedade do futuro (R. Moreno \& N. R. Saraiva, trads.). São Paulo: Herder.

Turing, A. (1950). "Computing Machinery and Intelligence. Mind, LIX(236), 433-460. doi:10.1093/mind/LIX.236.433. 